\title{
Occupational and environmental exposure to SARS- CoV-2 in and around infected mink farms
}

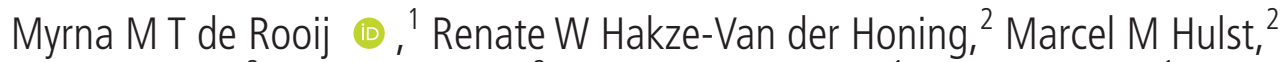 \\ Frank Harders, ${ }^{2}$ Marc Engelsma, ${ }^{2}$ Wouter van de Hoef, ${ }^{1}$ Kees Meliefste, ${ }_{1}$ \\ Sigrid Nieuwenweg, ${ }_{1}^{1}$ Bas B Oude Munnink, ${ }^{3}$ Isabella van Schothorst, ${ }^{1}$ \\ Reina S Sikkema, ${ }^{3}$ Arco N van der Spek, ${ }_{1}^{4}$ Marcel Spierenburg, ${ }_{1}^{4}$ Jack Spithoven, ${ }_{1}$ \\ Ruth Bouwstra, ${ }^{5}$ Robert-Jan Molenaar, ${ }^{5}$ Marion Koopmans, ${ }^{3}$ Arjan Stegeman, ${ }^{6}$ \\ Wim H M van der Poel, ${ }^{2}$ Lidwien A M Smit (1) ${ }^{1}$
}

\begin{abstract}
- Additional supplemental material is published online only. To view, please visit the journal online (http://dx.doi. org/10.1136/oemed-2021107443).
\end{abstract}

${ }^{1}$ Institute for Risk Assessment Sciences, Utrecht University, Utrecht, The Netherlands ${ }^{2}$ Wageningen Bioveterinary Research, Lelystad, The Netherlands

${ }^{3}$ Department of Viroscience, Erasmus MC, Rotterdam, The Netherlands

${ }^{4}$ Netherlands Food and Consumer Product Safety Authority, Utrecht, The Netherlands

${ }^{5} \mathrm{GD}$ Animal Health, Deventer, The Netherlands

${ }^{6}$ Farm Animal Health, Utrecht University, Utrecht, The Netherlands

Correspondence to Dr Myrna M T de Rooij, Utrecht University Institute for Risk Assessment Sciences, Utrecht, The Netherlands; m.m.t.derooij@uu.nl

Received 4 February 2021 Accepted 29 June 2021 Published Online First 30 July 2021

Check for updates

(C) Author(s) (or their employer(s)) 2021. No commercial re-use. See rights and permissions. Published by BMJ.

To cite: de Rooij MMT Hakze-Van der

Honing RW, Hulst MM,

et al. Occup Environ Med

2021:78:893-899.

\section{ABSTRACT}

Objective Unprecedented SARS-CoV-2 infections in farmed minks raised immediate concerns regarding transmission to humans and initiated intensive environmental investigations to assess occupational and environmental exposure.

Methods Air sampling was performed at infected Dutch mink farms, at farm premises and at nearby residential sites. A range of other environmental samples were collected from minks' housing units, including bedding materials. SARS-CoV-2 RNA was analysed in all samples by quantitative PCR.

Results Inside the farms, considerable levels of SARSCoV-2 RNA were found in airborne dust, especially in personal inhalable dust samples (approximately 1000-10 000 copies $/ \mathrm{m}^{3}$ ). Most of the settling dust samples tested positive for SARS-CoV-2 RNA (82\%, 75 of 92). SARS-CoV-2 RNA was not detected in outdoor air samples, except for those collected near the entrance of the most recently infected farm. Many samples of minks' housing units and surfaces contained SARS-CoV-2 RNA. Conclusions Infected mink farms can be highly contaminated with SARS-CoV-2 RNA. This warns of occupational exposure, which was substantiated by considerable SARS-CoV-2 RNA concentrations in personal air samples. Dispersion of SARS-CoV-2 to outdoor air was found to be limited and SARSCoV-2 RNA was not detected in air samples collected beyond farm premises, implying a negligible risk of environmental exposure to nearby communities. Our occupational and environmental risk assessment is in line with whole genome sequencing analyses showing mink-to-human transmission among farm workers, but no indications of direct zoonotic transmission events to nearby communities.

\section{INTRODUCTION}

The COVID-19 pandemic has its grip on the world. After the initial animal-to-human jump, human-to-human transmission took off. Several incident cases of human-to-animal transmission have been reported, ${ }^{1}$ but large outbreaks among commercially kept animals were not reported until minks (Neovison vison) at Dutch fur farms were found to be infected in April 2020. ${ }^{2}$ Subsequently,

\section{Key messages}

What is already known about this subject?

- SARS-CoV-2 infections in farmed minks were first observed in the Netherlands and later in other countries worldwide.

- This raised concerns regarding environmental transmission of SARS-CoV-2 from minks to farm workers and the general population living in the vicinity of the infected farms.

What are the new findings?

- Our intensive environmental investigations showed high levels of SARS-CoV-2 RNA contamination inside infected mink farms and considerable SARS-CoV-2 RNA concentrations in personal air samples, warning for occupational exposure among farm workers.

- Dispersion of SARS-CoV-2 to outdoor air was found to be limited and SARS-CoV-2 RNA was not detected in air samples collected beyond farm premises, implying a negligible risk of environmental exposure to nearby communities.

How might this impact on policy or clinical practice in the foreseeable future?

- Given the risk of interspecies transmission of SARS-CoV-2 between minks and humans, COVID-19 preventive measures and strict biosecurity are essential in mink farming.

- Once a mink farm is infected by SARSCoV-2, the whole farm should be considered contaminated, which necessitates intensive precautionary measures, including proper cleaning/disinfecting, even in the period after culling.

SARS-CoV-2 outbreaks in mink farms occurred worldwide, ${ }^{3-5}$ and transmission experiments with ferrets $^{6-8}$ show that SARS-CoV-2 is efficiently transmitted between minks and related species.

The occurrence of an unprecedented SARSCoV-2 infection in farmed minks raised immediate concerns regarding human health, both for the farm worker population and for neighbouring residents, and in view of global health considering the potential 
evolution of SARS-CoV-2 by large-scale animal passage. Therefore, a One Health approach was deployed to gain insight into the (genomic) epidemiology, sources and modes of transmission, and the associated human health risks. ${ }^{29} 10$ Using whole genome sequencing, evidence was provided of SARS-CoV-2 transmission from humans to minks, between minks, and from minks back to humans. ${ }^{9}$ Both in the Netherlands ${ }^{9}$ and Denmark, ${ }^{11}$ widespread transmission between farms occurred, with yet unknown mode of transmission.

In this paper, we describe intensive environmental investigations in and around the first SARS-CoV-2-infected mink farms notified in the Netherlands to better understand occupational and environmental health risks for workers and neighbouring residents. The study objectives were the following:

- To measure SARS-CoV-2 exposure by personal and stationary air sampling in mink farms.

- To study potential dispersion of SARS-CoV-2 to ambient environment by means of outdoor air sampling.

- To assess SARS-CoV-2 contamination of surfaces and materials sampled from minks' housing units.

\section{METHODS}

\section{Investigated farms}

On 23 April, SARS-CoV-2 infection was established at the first Dutch farm, NB1, which has two separate locations (NB1A and NB1B, $115 \mathrm{~m}$ apart). Two days later, another farm tested positive, NB2, situated at a $14 \mathrm{~km}$ distance from NB1. Both NB1 and NB2 experienced increased mortality among minks, coinciding with respiratory signs starting in the first half of April. ${ }^{29} 10$ From 28 April onwards, environmental sampling started at both farms. On 6 May, two additional farms tested positive, NB3 and NB4. NB4, in contrast to the other farms, appeared to be more recently infected at the time of detection. ${ }^{2910}$ Therefore, NB4 was included for environmental sampling from 13 May onwards (see online supplemental methods A for additional information on the outbreaks, including a timeline and background information on husbandry practices).

\section{Design of environmental sampling}

Air sampling was performed by filter-based techniques whereby air is forced through a filter and particles present in the air, including potentially SARS-CoV-2-contaminated particles, are captured. To gain insight into potential differences related to particle size fraction, air sampling was performed in parallel to measure both particulate matter $10\left(\mathrm{PM}_{10}\right)$ and inhalable dust based on the European norm defined size fractions. ${ }^{12} 13$

We conducted long-term air sampling at both farms' premises and nearby residential sites to detect potential dispersion of SARS-CoV-2 to the outdoor environment. We also collected air samples and settling dust at the farms and sampled surfaces and materials from minks' housing units. Simultaneous upwind and downwind sampling around the mink houses was performed to assess dispersion. For this part of the study, we visited each farm once per week for 3 weeks (T1, T2, T3). For the more recent outbreak at NB4, long-term outdoor air sampling was performed for 3 weeks, while sampling inside the farm was done once. On 3 June, the Dutch government decided to cull all minks at all infected farms. To gain insight into potentially remaining environmental contamination after culling, NB4 was revisited 14 days postculling to collect samples.

\section{Multiple-day outdoor air sampling}

At the infected farms, consecutive 3-day to 5-day sampling of outdoor air was performed at a central position within $10 \mathrm{~m}$ from the (open) wall of the farm. Sampling of $\mathrm{PM}_{10}$ and inhalable dust was performed in parallel at a $1.50 \mathrm{~m}$ height (for technical details see online supplemental methods B). After the first measurement week at NB4, measurement equipment was installed at three additional locations (B, C, D) within short distances from the initial location (A), where positive samples had been detected (see online supplemental figure S1 for a map). At B, C and D, total suspended particles (undefined size fraction) were additionally sampled.

Three residential sites were included in repeated 7-day air sampling. Three consecutive measurements per site were performed in the vicinity of NB1 $(1500 \mathrm{~m})$ and NB2 $(1200 \mathrm{~m})$. In addition, a residential site in a mink-free area $(>70 \mathrm{~km}$ from NB1 and NB2) was included as a background location.

\section{Sampling inside farm and downwind/upwind \\ Air sampling}

Six-hour stationary air sampling and 8-hour personal air sampling were performed for both $\mathrm{PM}_{10}$ and inhalable dust in parallel (for technical details see online supplemental methods B and for pictures see online supplemental figure S2). Personal air samples were collected using portable pumps and sampling heads attached within the breathing zone of the fieldworker. Stationary air sampling was performed at a $1.50 \mathrm{~m}$ height at three spots distributed within the farm, which remained the same over time. The locations of the 6-hour air sampling outside the farm were based on the wind direction on the day of measurement. Upwind sampling was performed at a $50 \mathrm{~m}$ distance from the farm and downwind sampling at 10-20 $\mathrm{m}$ and $100 \mathrm{~m}$ distance.

\section{Settling dust sampling}

Settling dust sampling was performed using electrostatic dust fall collectors (EDCs), which are sterilised electrostatic cloths (polyester electrostatic cloth; Albert Heijn, Zaandam, The Netherlands) placed in a disposable holder. ${ }^{14}$ EDCs were placed at 11 spots distributed throughout the farm. EDCs were placed in proximity $(<0.40 \mathrm{~m})$ of the minks by placing them on currently unused top layers of minks' housing units (1.60 m height). At NB1, some EDCs could also be placed farther away from the minks (several metres) by placing these on hanging plates or on a stand positioned in an empty alley (see online supplemental methods B for details and online supplemental figure S2 for pictures). After 1 week, the exposed EDCs were collected and replaced by new EDCs.

\section{Sampling of minks' housing units}

Per farm visit, a minimum of 10 minks' housing units were sampled, including those of recently deceased minks ( $<2$ days) and at least three alive minks (see online supplemental methods B for details and online supplemental figure S3 for pictures). In short, swipes were collected of the materials settled on the hardboard border at the front of the housing unit. Bedding materials, consisting of straw/hay, were collected from the night/nest box. Food residues were scraped off the top of the cage, where minimally once a day fresh food is placed. Swabs were taken of the rim of the drinker cup. If present, faecal materials were collected from the cage, otherwise from the floor beneath the cage.

\section{Procedures and analyses}

For details on the procedures and analyses, see online supplemental methods C. In short, each fieldwork day, all samples were immediately stored after collection at $4^{\circ} \mathrm{C}$ and directly brought to a biosafety level (BSL)-2 laboratory, where samples 
Table 1 Overview of SARS-CoV-2 RNA in particulate matter 10 and inhalable dust samples collected at mink farms at a later phase of the ongoing SARS-CoV-2 outbreak

\begin{tabular}{|c|c|c|c|c|c|c|c|c|c|c|}
\hline Timepoint & Date & Farm & \multicolumn{3}{|c|}{ 6-hour stationary sampling inside farm } & \multicolumn{3}{|c|}{ 8-hour personal sampling inside farm } & \multicolumn{2}{|c|}{$\begin{array}{l}\text { 6-hour stationary sampling } \\
\text { outside }\end{array}$} \\
\hline 1 & 28 April 2020 & NB1 & $1 / 3$ & $2.4 \times 10^{3}$ & $0 / 3$ & $\begin{array}{l}\text { Not } \\
\text { collected }\end{array}$ & NA & Not collected & $0 / 3$ & $0 / 3$ \\
\hline 1 & 2 May 2020 & NB1B & $1 / 3$ & $3.8 \times 10^{3}$ & $0 / 3$ & $1 / 2$ & $4.6 \times 10^{3}$ & Not collected & $0 / 3$ & $0 / 3$ \\
\hline 2 and 3 & 5-16 May 2020 & $\begin{array}{l}\text { NB1A, NB2, } \\
\text { NB1B }\end{array}$ & $0 / 18$ & Non-detects & Not applicable & $0 / 12$ & Non-detects & Not applicable & $0 / 18$ & Not applicable \\
\hline
\end{tabular}

All 4-day outdoor air samples collected between 28 April 2020 and 21 May 2020 at NB1A, NB1B and NB2 at their premises: SARS-CoV-2 RNA not detected.

NA, not applicable.

were prepared for storage at $-80^{\circ} \mathrm{C}$ on the same day. Samples were transported in batches on dry ice to another laboratory (BSL-2/3) for RNA extraction and quantitative PCR analyses for SARS-CoV-2. Virus isolation was attempted from air samples with a cycle threshold $(\mathrm{Ct})$ value below 32 .

Data processing and analyses were performed using RStudio (V.3.6.3). ${ }^{15}$ For the purpose of quantification, viral load in positive samples was computed and expressed in number of copies per standard unit (see online supplemental table S1). Multivariable modelling was performed to explore the associations with determinants. Censored regression analyses (parametric survival on log-10transformed outcomes due to otherwise skewed distribution) were performed on bedding material samples, swipes and EDCs. Estimates of associations were raised to the power of 10 to represent ratios in viral load. On faecal material samples and drinker cup swabs, logistic regression analyses (detection vs non-detection) were performed (as only a limited percentage of samples were positive) and the associations expressed in OR. For all models, assumptions were checked, including distribution of residuals.

\section{RESULTS}

\section{Air samples}

Farms NB1A, NB1B and NB2

At the first farm visit, SARS-CoV-2 RNA was detected inside each farm in one out of three 6-hour inhalable dust samples (see table 1). At farm NB1B, personal sampling was also performed during the first visit, of which one of the two 8-hour inhalable dust samples tested positive. Quantification of these four positive active air samples showed concentrations ranging from $2.4 \times 10^{3} \mathrm{RNA}$ copies $/ \mathrm{m}^{3}$ to $4.9 \times 10^{3} \mathrm{RNA}$ copies $/ \mathrm{m}^{3}$ (Ct range: 35-36). All of the parallel collected $\mathrm{PM}_{10}$ samples inside the farm and all other inhalable dust and $\mathrm{PM}_{10}$ air samples inside or near the mink houses were negative.

SARS-CoV-2 RNA was detected in a high number of settling dust samples (75 out of $92,82 \%$; median virus load $7.4 \times 10^{4}$ copies $/ \mathrm{m}^{2}$ ). All EDCs deployed at the first farm visit were positive ( $\mathrm{Ct}$ range: 25.1-34.6) at all three farms, with viral RNA loads ranging from $1.6 \times 10^{4}$ to $2.2 \times 10^{7}$ copies $/ \mathrm{m}^{2}$ per day sampled (see figure 1 ). At $\mathrm{NB} 2$, all EDCs deployed at the second and third farm visits were also all positive; at T2 (1 week after T1) at NB1A and NB1B, the percentage positives dropped to $73 \%$ and $80 \%$, respectively, and further to $64 \%$ and $27 \%$ at T3. The results of the multivariable modelling (see online supplemental table S2) showed a significant $(\mathrm{p}<0.05)$ decrease in viral RNA load over time at all three farms (factor 2.7 weeks 2 vs 1 , factor 5 weeks 3 vs 2). Furthermore viral RNA loads in EDCs placed in very close proximity $(<0.40 \mathrm{~m})$ to minks were on average 2.3 times higher than those farther away from animal cages $(\mathrm{p}<0.05)$.

\section{Residential sites}

All of the consecutively collected 7-day ambient air samples of $\mathrm{PM}_{10}$ at the three residential sites (three samples per site) were negative for SARS-CoV-2.

\section{Farm NB4}

Of the air samples collected at farm NB4, three out of six 6-hour inhalable dust samples and both 8-hour personal inhalable dust

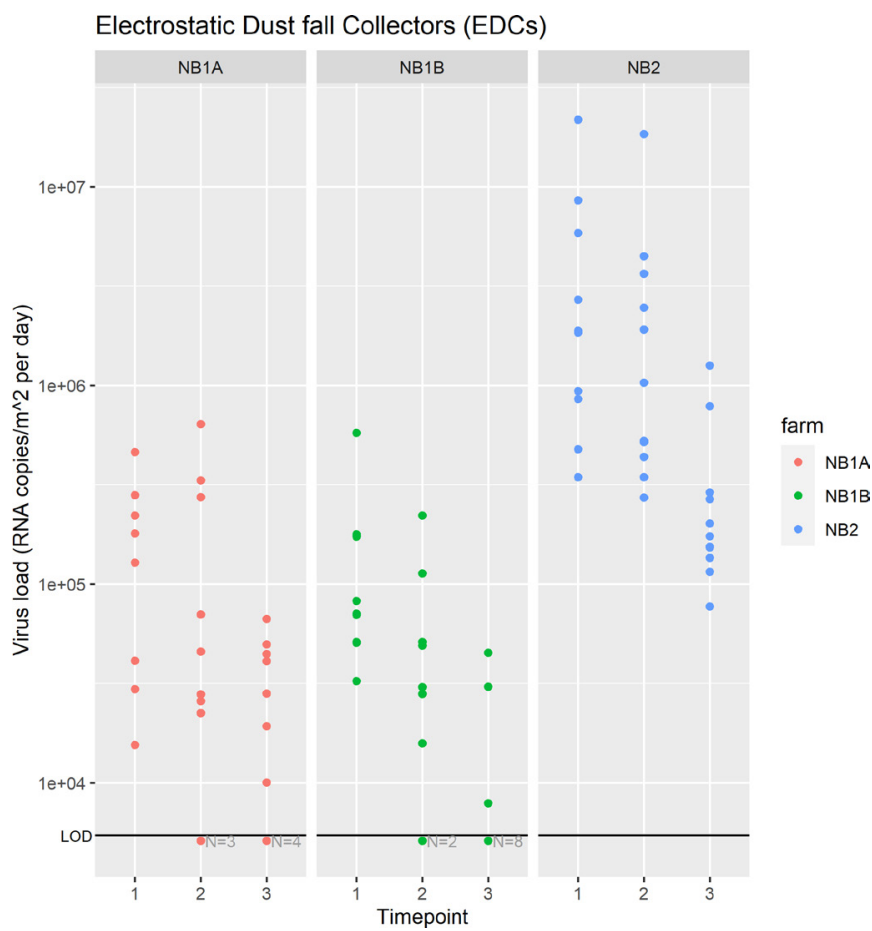

Figure 1 Overview of viral load in settling dust samples per farm over time collected by means of electrostatic dust fall collectors (EDCs). Percentiles: 25th, 50th and 75th of the virus load detected in EDCs of 2.16E $+04,7.40 \mathrm{E}+04$ and 3.68E +05 , respectively. LOD, limit of detection. 
Table 2 Overview of SARS-CoV-2 RNA in particulate matter 10 and inhalable dust samples collected at a mink farm (NB4) during a more acute phase of SARS-CoV-2 outbreak

\begin{tabular}{|c|c|c|c|c|c|c|c|}
\hline \multirow[b]{2}{*}{ Date } & \multirow[b]{2}{*}{ Measurement } & \multicolumn{2}{|l|}{ Inhalable } & \multicolumn{2}{|c|}{ Particulate matter 10} & \multicolumn{2}{|c|}{ Total suspended particles } \\
\hline & & Non-detect(s) & $\begin{array}{l}\text { Positive sample(s): } \\
\text { virus concentration } \\
\left(\text { RNA copies } / \mathrm{m}^{3}\right)\end{array}$ & Non-detect(s) & $\begin{array}{l}\text { Positive sample(s): } \\
\text { virus concentration } \\
\left(\text { RNA copies } / \mathrm{m}^{3} \text { ) }\right.\end{array}$ & Non-detect(s) & $\begin{array}{l}\text { Positive sample(s): } \\
\text { virus concentration } \\
\left.\text { (RNA copies } / \mathrm{m}^{3}\right)\end{array}$ \\
\hline 13 May 2020 & $\begin{array}{l}\text { Multiple-day outdoor: } \\
\text { spot A only }\end{array}$ & None & A: $7.1 \times 10^{2}$ & A & None & Not collected & Not collected \\
\hline 16 May 2020 & $\begin{array}{l}\text { Multiple-day outdoor: } \\
\text { spot A only }\end{array}$ & None & $A: 3.6 \times 10^{3}$ & A & None & Not collected & Not collected \\
\hline \multirow[t]{2}{*}{19 May 2020} & $\begin{array}{l}\text { 6-hour indoor } \\
\text { stationary (sampling } \\
\text { spots I, II, III, IV, V, VI) }\end{array}$ & $\mathrm{I}, \mathrm{II}, \mathrm{V}$ & $\begin{array}{l}\text { III: } 6.6 \times 10^{3} \\
\text { IV: } 9.8 \times 10^{3} \\
\text { VI: } 1.9 \times 10^{4}\end{array}$ & $\mathrm{I}, \mathrm{II}, \mathrm{III}, \mathrm{V}$ & $\begin{array}{l}\text { IV: } 5.5 \times 10^{3} \\
\text { VI: } 2.5 \times 10^{3}\end{array}$ & Not collected & Not collected \\
\hline & $\begin{array}{l}\text { 8-hour indoor } \\
\text { personal (person } \mathrm{X} \\
\text { and person } \mathrm{Y} \text { ) }\end{array}$ & None & $\begin{array}{l}X: 4.5 \times 10^{4} \\
Y: 4.3 \times 10^{4}\end{array}$ & None & $\begin{array}{l}X: 2.0 \times 10^{4} \\
Y: 3.0 \times 10^{3}\end{array}$ & Not collected & Not collected \\
\hline 21 May 2020 & $\begin{array}{l}\text { Multiple-day outdoor: } \\
\text { expanded (spot A+ } \\
\text { B, C, D) }\end{array}$ & None & $A: 2.6 \times 10^{3}$ & None & A: $1.1 \times 10^{2}$ & $A, C, D$ & B: $6.9 \times 10^{2}$ \\
\hline 25 May 2020 & $\begin{array}{l}\text { Multiple-day outdoor: } \\
\text { expanded (spot A+ } \\
\text { B, C, D) }\end{array}$ & $A, B, C, D$ & None & A & None & $B, D$ & $\begin{array}{l}A: 4.5 \times 10^{2} \\
C: 3.1 \times 10^{2}\end{array}$ \\
\hline 28 May 2020 & $\begin{array}{l}\text { Multiple-day outdoor: } \\
\text { expanded (spot A+ } \\
B, C, D \text { ) }\end{array}$ & $A, D$ & None & None & A: $1.2 \times 10^{3}$ & D & $\begin{array}{l}\text { A: } 4.8 \times 10^{3} \\
\text { B: } 1.7 \times 10^{3} \\
\text { C: } 2.7 \times 10^{2}\end{array}$ \\
\hline
\end{tabular}

$\mathrm{I}, \mathrm{II}, \mathrm{III}, \mathrm{IV}, \mathrm{V}, \mathrm{VI}$ : stationary indoor air sampling spots (see online supplemental figure S1 for a map of the layout of the farm and measurement spots.

$A, B, C, D$ : stationary outdoor air sampling spots (see online supplemental figure $S 1$ for a map of the layout of the farm and measurement spots).

$X$, personal air sampling of fieldworker $X ; Y$, personal air sampling of fieldworker $Y$.

samples were positive (see table 2). Concentrations measured in the personal air samples were higher compared with the stationary air samples, roughly $4 \times 10^{5}$ copies $/ \mathrm{m}^{3}(\mathrm{Ct}: 31.7 / 31.8)$ compared with $7 \times 10^{3}$ to $2 \times 10^{4}$ copies $/ \mathrm{m}^{3}$ (Ct range: $33.0-34.4$ ). Two out of six stationary $\mathrm{PM}_{10}$ samples and both personal $\mathrm{PM}_{10}$ samples were positive, with lower concentrations compared with the inhalable dust samples.

In 4-day outdoor air samples collected at the premises, SARSCoV-2 RNA was detected at measurement location A, positioned within $1.5 \mathrm{~m}$ of the farm's open entrance, but also at measurement spots B and C, positioned within $10 \mathrm{~m}$ from the farm's open entrance. $\mathrm{PM}_{10}$ samples collected at spot A were either negative or contained limited levels of SARS-CoV-2 RNA. Inhalable dust and total suspended particles samples contained levels of SARS-CoV-2 RNA ranging from $3 \times 10^{2}$ to $5 \times 10^{3}$ copies $/ \mathrm{m}^{3}$ (Ct range: $32.3-35.0$ ). At location D, $20 \mathrm{~m}$ from the entrance, all samples were negative.

\section{Samples of minks' housing units Preculling}

SARS-CoV-2 RNA was detected in all swipes of minks' housing units $\left(n=99\right.$, lowest Ct: 21.5, median virus load $6.0 \times 10^{6}$ copies). A high percentage of bedding materials $(83 \%, 78$ out of 94 , lowest Ct: 15.9 , median virus load $8.2 \times 10^{5}$ copies) were also positive, and to a lesser extent faecal materials (54\%, 51 out of 95, lowest Ct: 24.6). Some swabs of the drinker cups and few food residues were positive (31\%, 30 out of 97 , lowest Ct: $24.8 ; 10 \%, 9$ out of 90 , lowest Ct 28.9, respectively). Significant differences in viral load in swipes and bedding materials were observed between farms (see table 3 and online supplemental figure S4). Viral load was estimated to be 7 times higher in swipes and 45 times higher in bedding materials at NB4 compared with NB1A and with even larger differences when compared with NB1B and NB2. Higher viral loads were observed in the bedding materials of the housing units belonging to recently deceased minks versus minks that were still alive. Significantly lower odds of detection in faecal materials and swabs of drinker cups were observed for sampling at later timepoints compared to the first timepoint (table 3). In swabs of drinker cups, higher odds of detection were also associated with recently deceased minks.

\section{Postculling}

Samples collected postculling at NB4 of the same housing units sampled preculling showed a clearly decreased detection of viral RNA. However, RNA was still measurable in 14\% of the swipes and $21 \%$ of faecal materials, and especially in bedding materials (top layer 57\%, bottom layer 85\%). A large drop in viral load postculling versus preculling was observed in bedding materials' top layer (factor 100 difference, $\mathrm{p}<0.001$ ), and for the bottom layer this drop was considerably smaller (factor 10 difference, $\mathrm{p}<0.05$ ) (see online supplemental table S3 and figure S5).

\section{Controls}

None of the field blanks collected (minimally 1 per 10 samples) tested positive. Fieldworkers remained SARS-CoV-2-negative throughout the study; they always wore personal protective equipment (PPE), including full face mask.

\section{DISCUSSION}

Air and surfaces at infected mink farms were found to be highly contaminated with SARS-CoV-2 RNA. Airborne inhalable dust contaminated with SARS-CoV-2 RNA was detected inside each investigated farm. Most settling dust samples tested positive, as well as many samples of minks' housing units. In contrast to the high level of contamination detected inside the farm, no SARSCoV-2 RNA or incidental low concentrations were detected in outdoor air. This raises caution for occupational health risks in infected farms and suggests a negligible role of SARS-CoV-2 dispersion by air in community transmission. 
Table 3 Results of multivariable modelling on SARS-CoV-2 RNA in the different sample types of mink housing units

\begin{tabular}{|c|c|c|c|c|}
\hline \multirow[b]{3}{*}{ Variable } & \multicolumn{2}{|l|}{ Virus load (copies) } & \multicolumn{2}{|c|}{ Virus presence (non-detect/detect) } \\
\hline & Swipe & Bedding material & Faecal material & Drinker cup swab \\
\hline & Ratio $(95 \% \mathrm{Cl})$ & Ratio $(95 \% \mathrm{Cl})$ & OR $(95 \% \mathrm{Cl})$ & OR $(95 \% \mathrm{Cl})$ \\
\hline Farm NB1A (indicator) & - & - & - & - \\
\hline Farm NB1B & $0.43^{*}(0.23$ to 0.81$)$ & $1.7(0.25$ to 11$)$ & 0.31 (0.081 to 1.11$)$ & $0.28(0.061$ to 1.09$)$ \\
\hline Farm NB2 & $0.37^{\star}(0.20$ to 0.68$)$ & $0.22(0.03$ to 1.5$)$ & $0.16^{*}(0.042$ to 0.56$)$ & $0.15^{*}(0.031$ to 0.58$)$ \\
\hline Farm NB4 & $6.80^{*}(2.90$ to 16.0$)$ & $45^{*}(3.0$ to 670$)$ & $0.19(0.025$ to 1.28$)$ & $1.92(0.296$ to 14.32$)$ \\
\hline Timepoint 1 (indicator) & - & - & - & - \\
\hline Timepoint 2 & $1.10(0.60$ to 2.00$)$ & $1.7(0.24$ to 11$)$ & 0.4 (0.115 to 1.28$)$ & $0.25^{*}(0.058$ to 0.97$)$ \\
\hline Timepoint 3 & $0.57(0.31$ to 1.10$)$ & $0.86(0.12$ to 6.0$)$ & $0.11^{*}(0.027$ to 0.38$)$ & $0.22^{*}(0.045$ to 0.88$)$ \\
\hline Mink recently deceased (vs live mink) & $1.60(0.95$ to 2.60$)$ & $59 *(12$ to 300$)$ & $0.47(0.161$ to 1.31$)$ & $7.76^{*}(2.156$ to 38.32$)$ \\
\hline
\end{tabular}

Number of samples (percentage above limit of detection) collected per type: swipe $n=99(100 \%)$, bedding material $n=94(83 \%)$, faecal material $n=95(54 \%)$ and drinker cup swab $\mathrm{n}=97(31 \%)$.

Censored regression was applied for swipes and bedding material samples. Associations expressed in ratio=estimate of associations to the power of 10 to represent ratio in viral load.

Logistic regression was applied for faecal material samples and swabs of the drinker cups due to the limited number of samples above the limit of detection. Associations expressed in OR.

${ }^{*} \mathrm{P}<0.05$.

In the course of the outbreak, effective SARS-CoV-2 spread among minks was observed, as well as transmission between minks and farm workers. ${ }^{2910}$ High levels of environmental contamination inside the farm suggest a potential role of environmental exposure in mink-to-mink and mink-to-human transmission. The intensity of animal handling by farm workers varies over the course of a year and is typically solely high in April to June, which is the period from end of gestation to weaning. Animal handling is a likely cause of exposure among farm workers; however, zoonotic transmission events were also indicated in months when no/little animal handling was performed. ${ }^{9}$ SARSCoV-2-contaminated airborne particles of sizes smaller than $10 \mu \mathrm{m}$ and larger were detected in the air within the breathing zone of fieldworkers who performed environmental sampling. Both smaller-sized and larger-sized airborne particles should be considered relevant to health as deposition of inhaled SARS$\mathrm{CoV}$-2-contaminated particles anywhere along the respiratory tract has the potential to initiate infection. ${ }^{16}$ Considerable RNA concentrations were measured in the air within fieldworkers' breathing zone, which probably underestimate the exposure of actual farm workers as they do have direct contact with the animals. The observed high levels of contamination throughout the farms and the likelihood of a mink-to-human transmission, as demonstrated by whole genome sequencing research, called for implementation of improved biosecurity, hygienic measures and wearing of PPE by farm workers and was effectuated by the Dutch authorities as of May 2020. ${ }^{17-19}$

Airborne SARS-CoV-2 RNA could be a result of direct shedding into the air by an infectious mink (eg, via sneezing, breathing) and/or indirectly via shedding into the environment and subsequently becoming airborne of stirred up particles (eg, dust particles arising from the bedding material). SARS-CoV-2 experiments with ferrets showed transmission via respiratory droplets, aerosols and/or fomites between ferrets placed apart at $10 \mathrm{~cm}^{6}$ and $>1 \mathrm{~m}^{8}$ We performed stationary air sampling at a fixed distance of $50 \mathrm{~cm}$ from the nearest minks and personal air sampling naturally at varying distances of up to as close as $10 \mathrm{~cm}$, and thus we could have detected direct shedding of respiratory droplets and/or aerosols. Co-occurrence of indirect routes of airborne spread of contaminated particles is also highly likely, given high levels of contamination observed in matrices easily becoming airborne, such as bedding materials, and presence of airborne dust-generating events (eg, uncontrolled air/wind flows, and movements of animals, food carts and humans). Visual inspections of dust that had settled on EDCs over the course of a week confirmed the high level of dust inside these farms. SARS-CoV-2 RNA loads were high in settling dust samples even at distances of several metres from the animals.

Environmental RNA load is the net result of shedding rates by SARS-CoV-2 infectious minks and processes such as degradation or removal/cleaning. Seroprevalence among minks at the investigated farms was high, ${ }^{10}$ indicating many had been infectious at some point in time. The rate of RNA decay is influenced by factors such as temperature and humidity, chemical exposure (eg, reactive oxygen species, alkylating agents) and radiation exposure (eg, ultraviolet radiation), ${ }^{20}$ and depending on the environmental matrix more or less decay may take place. SARSCoV-2 RNA was still detectable in the environment 2 weeks after all animals were culled, similar to what has been observed in an outbreak investigation performed on a cruise ship. ${ }^{21}$ Farm cleaning is performed only sporadically; the last time the minks' housing units were cleaned was months before the outbreak started and thus the results were not affected by a cleaning regimen. Proper cleaning/disinfecting of such a contaminated environment is difficult, as also clearly shown by the remaining SARS-CoV-2 RNA loads. These results, in light of the current many unknowns to actually characterise infection risk, warn of extended precaution in the period after culling.

These unprecedented SARS-CoV-2 infections in farmed minks raised immediate concerns regarding public health, which resulted in government-imposed enclosure of the area around the farms awaiting results of outdoor air investigations. In contrast to the high indoor environmental contamination, none of the 54 outdoor air samples collected at NB1A, NB1B and NB2 tested positive, implying that SARS-CoV-2 RNA was either not present in outdoor air, or if present then in very low concentrations (limit of detection $\sim 10$ copies $/ \mathrm{m}^{3}$ of air). At NB4, the farm in a more acute phase of the SARS-CoV-2 outbreak, SARS-CoV-2 RNA was detected in outdoor air. Results clearly showed notable RNA concentrations in the air near the open entrance $(<1.5 \mathrm{~m})$ and a considerable drop in concentrations several metres further. Outside the farm premises, at a distance of $20 \mathrm{~m}$ from the minks, no RNA was detected. Outdoor air SARS-CoV-2 RNA concentrations in $\mathrm{PM}_{10}$ were lower compared with inhalable 
dust/total suspended particles. Considering natural dispersion, large particles, especially $>30 \mu \mathrm{m}$, deposit quickly and typically do not reach distances farther than tens of metres. ${ }^{22}{ }^{23}$ Particles sized $10 \mu \mathrm{m}$ or smaller are able to disperse further, but given the measured concentrations and the observed strong reduction over short distances it is unlikely that a potential risk of infection exists beyond farm premises. Furthermore, various outdoor environmental factors unfavourable to viruses, such as ultraviolet radiation, must be considered. Consequently, the direct environmental health risk to passers-by or neighbouring residents of infected farms is expected to be negligible. This substantiates findings by whole genome sequencing ${ }^{9}$ indicating no spillover to people living in the surroundings. Sequences of patients with COVID-19 living in the vicinity of infected mink farms did not cluster with sequences identified in minks and mink farmers, but reflected the general diversity seen in the Dutch databases of patients with COVID-19. ${ }^{9}$ Outbreak investigations performed around infected mink farms in Denmark suggested that virus transmission to the local community was caused by social contacts of infected mink farmers/workers with others. ${ }^{11}$ Our findings are not only relevant considering public health, but also suggest transmission by air as an unlikely route for the widespread and still unexplained ongoing farm-to-farm transmission.

The main limitation of our study is the lack of insight into SARS-CoV-2 viability. Many samples tested positive for SARSCoV-2 RNA with considerable levels, but no insight was gained on infectivity. Viability testing was attempted on two air samples with the highest RNA concentrations, but attempts were unsuccessful as expected. On top of viability testing in general being challenging, ${ }^{24}$ the chosen measurement strategy, including the air sampling techniques deployed, was highly suited for RNA detection but inappropriate for viability assessment. To actually assess viability of a pathogen when in the air is extremely challenging as the sampling itself stresses the pathogens (to a more or lesser extent depending on the technique). ${ }^{25}{ }^{26}$ Nevertheless, research performed in experimental settings ${ }^{27} 28$ and in a hospital situation ${ }^{29}$ was able to identify viable SARS-CoV-2 in air samples. In aerosols generated under laboratory conditions, SARS-CoV-2 remained stable for several hours ( $<16$ hours). ${ }^{27}{ }^{28}$ These findings support the potential risk of infection due to transmission via air. Another limitation is the unknown recovery efficiency of SARS-CoV-2 RNA from the environmental samples. A recent study by Minich $e t a l^{30}$ on SARS-CoV-2 RNA recovery from swabs reported overall good recovery rates, and many factors were found to play a role (including swab type, storage solution, molecular processing), but especially the sampling itself. In our study, these factors remained the same throughout the study period, including collection of samples, which was strictly performed according to protocol by the same fieldworker, preventing potential differential errors. Absolute SARS-CoV-2 RNA levels in our study will be more or less underestimated depending on recovery efficiency. More experimental research on aspects such as viability and recovery of SARS-CoV-2 while in the environment is warranted to address important knowledge gaps, eventually enabling risk characterisation of SARS-CoV-2 environmental contamination.

In conclusion, infected mink farms can be highly contaminated with SARS-CoV-2 RNA in airborne dust, on surfaces and in various other environmental matrices. Dispersion of SARS$\mathrm{CoV}-2$ to outdoor air was limited, which implies a negligible risk of environmental exposure to neighbouring residents.
Acknowledgements We thank the farm owners for their cooperation. We would like to acknowledge Sophie van Oort, Wietske Dohmen, Angèle Timan and Monique Tersteeg-Zijderveld for their contribution to the laboratory analyses. Lützen Portengen is thanked for helping with statistical analyses.

Contributors Conception and design: MMTdR, LAMS, BBOM, RS, AS, MS, RB, R-JM, MK, AS and WHMvdP. Data collection and laboratory work: MMTdR, RWH-VDH, MMH, FH, ME, WvdH, KM, SN, IVS, JS and LAMS. Data analyses and interpretation: MMTdR together with LAMS, with additional input from R-JM, MK, AS and WHMvdP. Preparation of the manuscript: MMTdR, together with LAMS, with additional input from RWH-VDH, MMH, FH, ME, WvdH, KM, SN, BBOM, IvS, RS, ANvdS, MS, JS, RB, R-JM, MK, AS and WHMvdP.

Funding This work was funded by the Netherlands Ministry of Agriculture, Nature and Foods.

Competing interests None declared.

\section{Patient consent for publication Not required.}

Ethics approval The Medical Research Ethics Committee (MREC) Utrecht confirmed that the Medical Research Involving Human Subjects Act (WMO) does not apply to (personal) air sampling and therefore an official approval of this study by the MREC Utrecht was not required under the WMO (protocol 20-385/C, reference number WAG/mb/20/021975).

Provenance and peer review Not commissioned; externally peer reviewed.

Data availability statement All data relevant to the study are included in the article or uploaded as supplementary information.

Supplemental material This content has been supplied by the author(s). It has not been vetted by BMJ Publishing Group Limited (BMJ) and may not have been peer-reviewed. Any opinions or recommendations discussed are solely those of the author(s) and are not endorsed by BMJ. BMJ disclaims all liability and responsibility arising from any reliance placed on the content. Where the content includes any translated material, BMJ does not warrant the accuracy and reliability of the translations (including but not limited to local regulations, clinical guidelines, terminology, drug names and drug dosages), and is not responsible for any error and/or omissions arising from translation and adaptation or otherwise

This article is made freely available for use in accordance with BMJ's website terms and conditions for the duration of the covid-19 pandemic or until otherwise determined by BMJ. You may use, download and print the article for any lawful, non-commercial purpose (including text and data mining) provided that all copyright notices and trade marks are retained.

\section{ORCID iDs}

Myrna M T de Rooij http://orcid.org/0000-0002-6560-4839

Lidwien A M Smit http://orcid.org/0000-0003-0292-0946

\section{REFERENCES}

1 Salajegheh Tazerji S, Magalhães Duarte P, Rahimi P, et al. Transmission of severe acute respiratory syndrome coronavirus 2 (SARS-CoV-2) to animals: an updated review. J Trans/ Med 2020;18:358.

2 Oreshkova N, Molenaar RJ, Vreman S, et al. SARS-CoV-2 infection in farmed minks, the Netherlands, April and may 2020. Euro Surveill 2020;25:1.

3 OIE. OIE - World Organisation for Animal Health. SARS-CoV-2 Events in animals, 2020. Available: https://www.oie.int/en/scientific-expertise/specific-informationand-recommendations/questions-and-answers-on-2019novel-coronavirus/events-inanimals/

4 Cahan E. COVID-19 hits U.S. mink farms after ripping through Europe. Science 2020.

5 WHO. SARS-CoV-2 mink-associated variant strain - Denmark. who.int, 2020. Available: https://www.who.int/csr/don/06-november-2020-mink-associated-sarscov2-denmark/en/

6 Richard M, Kok A, de Meulder D, et al. SARS-CoV-2 is transmitted via contact and via the air between ferrets. Nat Commun 2020;11:3496.

7 Shi J, Wen Z, Zhong G, et al. Susceptibility of ferrets, cats, dogs, and other domesticated animals to SARS-coronavirus 2. Science 2020;368:1016-20.

8 Kutter JS, de Meulder D, Bestebroer TM. SARS-CoV and SARS-CoV-2 are transmitted through the air between ferrets over more than one meter distance. bioRxiv 2020. doi:10.1101/2020.10.19.345363

9 Oude Munnink BB, Sikkema RS, Nieuwenhuijse DF, et al. Transmission of SARSCoV-2 on mink farms between humans and mink and back to humans. Science 2021;371:eabe5901

10 Molenaar RJ, Vreman S, Hakze-van der Honing RW, et al. Clinical and Pathological Findings in SARS-CoV-2 Disease Outbreaks in Farmed Mink (Neovison vison). Vet Pathol 2020;57:653-7.

11 Hammer AS, Quaade ML, Rasmussen TB, et al. SARS-CoV-2 transmission between mink (Neovison vison) and humans, Denmark. Emerg Infect Dis 2021;27:547-51. 
12 Comité Européen de Normalisation (CEN; European Committee for Standardization). EN 481: 1993 Workplace atmospheres - Size fraction definitions for measurement of airborne particles, 1993.

13 Comité Européen de Normalisation (CEN; European Committee for Standardization). EN 12341:1998 Air quality - Determination of the PM 10 fraction of suspended particulate matter - Reference method and field test procedure to demonstrate reference equivalence of measurement methods, 1998.

14 Noss I, Wouters IM, Visser M, et al. Evaluation of a low-cost electrostatic dust fall collector for indoor air endotoxin exposure assessment. App/ Environ Microbiol 2008;74:5621-7.

15 R.Core-Team. R: a language and environment for statistical computing, 2017. Available: https://www.r-project.org/

16 Sungnak W, Huang N, Bécavin C, et al. SARS-CoV-2 entry factors are highly expressed in nasal epithelial cells together with innate immune genes. Nat Med 2020;26:681-7.

17 Ministry of Agriculture Nature and Food Quality of the Netherlands. Kamerbrief over landelijke maatregelen op nertsenbedrijven [Note on national measures on mink farms]; May 2020. Rijksoverheid.nl, 2020. Available: https://www.rijksoverheid.nl/ documenten/kamerstukken/2020/05/28/kamerbrief-over-landelijke-maatregelen-opnertsenbedrijven [Accessed $21 \mathrm{Apr} 2021$ ]

18 Ministry of Agriculture Nature and Food Quality of the Netherlands. Regeling aanwijzing Sars-CoV-2 ivm volksgezondheid [Regulation on SARS-CoV-2 in connection with public health]; June 2020. Rijksoverheid.nl, 2020. Available: https:// www.rijksoverheid.nl/documenten/regelingen/2020/06/03/regeling-aanwijzing-sarscov-2-ivm-volksgezondheid [Accessed 21 Apr 2021].

19 Ministry of Agriculture Nature and Food Quality of the Netherlands. Kamerbrief stand van zaken SARS-CoV-2 bij nertsen [Note on update SARS-CoV-2 in minks]; July 2020. Rijksoverheid.nl, 2020. Available: https://www.rijksoverheid.nl/documenten/ kamerstukken/2020/07/20/kamerbrief-stand-van-zaken-sars-cov-2-bij-nertsen [Accessed 21 Apr 2021].
20 Barr JN, Fearns R. How RNA viruses maintain their genome integrity. J Gen Virol 2010;91:1373-87.

21 Yamagishi T, Ohnishi M, Matsunaga N, et al. Environmental sampling for severe acute respiratory syndrome coronavirus 2 during a COVID-19 outbreak on the diamond Princess cruise SHIP. J Infect Dis 2020;222:1098-102.

22 Godoy SM, Mores PL, Santa Cruz ASM, et al. Assessment of impact distances for particulate matter dispersion: a stochastic approach. Reliab Eng Syst Saf 2009;94:1658-65.

23 Huertas Cardozo Jl, Prato Sánchez DF. An experimental and numerical study of air pollution near unpaved roads. Air Qual Atmos Health 2019;12:471-89.

24 Jefferson T, Spencer EA, Brassey J. Viral cultures for COVID-19 infectivity assessment-a systematic review. medRxiv 2020. doi:10.1101/2020.08.04.20167932

25 Zhang XS, Duchaine C. SARS-CoV-2 and health care worker protection in low-risk settings: a review of modes of transmission and a novel airborne model involving inhalable particles. Clin Microbiol Rev 2020;34.

26 Wilson NM, Norton A, Young FP, et al. Airborne transmission of severe acute respiratory syndrome coronavirus-2 to healthcare workers: a narrative review. Anaesthesia 2020;75:1086-95.

27 van Doremalen N, Bushmaker T, Morris DH, et al. Aerosol and surface stability of SARS-CoV-2 as compared with SARS-CoV-1. N Engl J Med 2020;382:1564-7.

28 Fears AC, Klimstra WB, Duprex P, et al. Persistence of severe acute respiratory syndrome coronavirus 2 in aerosol suspensions. Emerg Infect Dis 2020;26:2168-71.

29 Lednicky JA, Lauzardo M, Fan ZH. Viable SARS-CoV-2 in the air of a hospital room with COVID-19 patients. medRxiv Prepr Serv Heal Sci 2020:2020.08.03.20167395.

30 Minich JJ, Ali F, Marotz C, et al. Feasibility of using alternative swabs and storage solutions for paired SARS-CoV-2 detection and microbiome analysis in the hospital environment. Microbiome 2021;9:25. 